\title{
A Numerical Investigation on the Effect of Gas Pressure on the Water Saturation of Compacted Bentonite-Sand Samples
}

\author{
Jiang-Feng Liu, ${ }^{1,2}$ Shuai-Bing Song, ${ }^{1}$ Jian Liu, ${ }^{3}$ Bing-Xiang Huang, ${ }^{4}$ Xu-Lou Cao, ${ }^{1}$ \\ Kai Zhang, ${ }^{1}$ and Frédéric Skoczylas ${ }^{5}$ \\ ${ }^{1}$ State Key Laboratory for Geomechanics and Deep Underground Engineering and School of Mechanics and Civil Engineering, \\ China University of Mining and Technology, Xuzhou 221116, China \\ ${ }^{2}$ State Key Laboratory of Geohazard Prevention and Geoenvironment Protection, Chengdu University of Technology, Chengdu, \\ Sichuan 610059, China \\ ${ }^{3}$ CNNC Beijing Research Institute of Uranium Geology (BRIUG), Beijing 100029, China \\ ${ }^{4}$ Key Laboratory of Deep Coal Resource Mining, Ministry of Education of China, China University of Mining and Technology, \\ Xuzhou 221116, China \\ ${ }^{5}$ Laboratoire de Mécanique de Lille (CNRS, LML) and École Centrale de Lille, CS 20048, 59651 Villeneuve-d’Ascq Cedex, France
}

Correspondence should be addressed to Jiang-Feng Liu; jeafliu@hotmail.com and Bing-Xiang Huang; huangbxcumt@outlook.com

Received 8 June 2017; Revised 19 September 2017; Accepted 8 October 2017; Published 27 December 2017

Academic Editor: Qinghui Jiang

Copyright (C) 2017 Jiang-Feng Liu et al. This is an open access article distributed under the Creative Commons Attribution License, which permits unrestricted use, distribution, and reproduction in any medium, provided the original work is properly cited.

\begin{abstract}
In deep geological disposal for high-level radioactive waste, the generated gas can potentially affect the sealing ability of bentonite buffers. There is a competition between water and gas: the former provides sealing by swelling bentonite, and the latter attempts to desaturate the bentonite buffer. Thus, this study focused on numerically modelling the coupling effects of water and gas on the water saturation and sealing efficiency of compacted bentonite-sand samples. Different gas pressures were applied to the top surface of an upper sample, whereas the water pressure on the bottom side of the lower sample was maintained at $4 \mathrm{MPa}$. The results indicated that gas pressure did not significantly affect the saturation of the bentonite-sand sample until $2 \mathrm{MPa}$. At $2 \mathrm{MPa}$, the degree of water saturation of the upper sample was close to 1.0. As the gas pressure increased, this influence was more apparent. When the gas pressure was $6 \mathrm{MPa}$ or higher, it was difficult for the upper sample to become fully saturated. Additionally, the lower sample was desaturated due to the high gas pressure. This indicated that gas pressure played an important role in the water saturation process and can affect the sealing efficiency of bentonite-based buffer materials.
\end{abstract}

\section{Introduction}

The management of high-level radioactive waste is an important issue for countries with nuclear power. Currently, deep geological disposal methods are used by most countries. In deep geological disposal systems, barriers include natural geological barriers and engineered barrier systems (EBSs). EBSs may comprise various subsystems or components, such as waste forms, canisters, buffers and backfills, seals, and plugs. Bentonite or bentonite-based materials (e.g., a bentonite/sand mixture was used in this study) have been used by several countries as buffer and backfill materials [17]. In most repository concepts, bentonite is only partially saturated. After the repository is closed, groundwater in the host formation will invade the bentonite barriers. Underground water seepage will cause bentonite swelling and consequently disposal pit sealing.

Nevertheless, in the long term, gases may be produced in the repository by several methods, such as metal corrosion, water radiolysis, and organic waste microbial degradation, which produce hydrogen, oxygen, methane, and carbon dioxide [8-10]. Over time, gas pressure will increase and build up if generation rates are high and transport is within the repository. This pressure may be sufficient to affect the repository structure and properties, particularly those of bentonite/sand mixtures. Water is favourable for the saturation of bentonite, whereas gas has the opposite effect. Therefore, the sealing provided by swollen bentonite competes with 
the effects of gas, which attempts to be desaturated and migrate through the buffer to the surrounding host rock and potentially the environment and simultaneously remove radionuclides [11].

In recent decades, researchers have tried to evaluate the sealing efficiency of engineered barriers. One approach is to measure the gas permeability of samples under different confining pressures [12-14]. Another approach is to measure the gas breakthrough pressure of samples under constant confining pressures [5, 6, 15-18]. Regarding these two approaches, one of the most important factors is the water saturation degree, which has a close relationship with the sealing ability of the samples. However, it is difficult to measure the degree of saturation of a sample during a traditional triaxial test because the sample cannot be removed from the triaxial cell during the test. Therefore, numerical modelling is a good method to evaluate the degree of saturation. Additionally, we can obtain the distribution of the degree of saturation in different potions of the sample.

At the time of writing, a few modelling studies have been performed to simulate gas/water transport in clayey materials. Fall et al. [19] utilized a coupled hydromechanical (HM) model to predict and analyse gas migration in sedimentary rock. This model considered elastic degradation due to microcracks or damage and mechanical damagecontrolled gas flow. Xu et al. [20] simulated gas migration in water-saturated argillaceous rock with a two-phase flow and a mechanics-coupled numerical model $\left(\mathrm{H}^{2} \mathrm{M}\right)$. In this model, intrinsic permeability and mechanical and hydraulic conditions were varied during the gas migration process. Gonzalez-Blanco et al. [21] simulated gas migration in a Cenozoic clay with a fully coupled hydromechanical model, which incorporated an embedded fracture permeability model. Additionally, other researchers performed a series of numerical modelling assays to determine gas migration in clayey materials $[16,22-24]$.

In situ water pressure is approximately 4-5 MPa, whereas gas pressure increases gradually and decreases again when breakthrough occurs. This indicates that a coupling effect exists between a constant water pressure and an increasing gas pressure. However, many researchers overlooked this phenomenon. Thus, our modelling aimed to reproduce the competition between water and gas and their coupling effects on the water saturation of bentonite-based buffers. This study is a supplementary work in conjunction with our other FORGE (Fate of Repository Gases) experiments [6]. The overall project aims to investigate and quantify gas generation and migration in the underground disposal of radioactive wastes.

\section{Theoretical Model}

2.1. Governing Equation. Flow in unsaturated medium is commonly described by the Richards equation [26-28]:

$$
\frac{\partial \theta_{\omega}}{\partial t}=\operatorname{di\tau }\left(K\left(\nabla h+F^{m}\right)\right)
$$

where $K$ is the hydraulic conductivity (Darcy law), $h$ is the hydraulic pressure, and $F^{m}$ is the vector of gravity (the value is -1 for the vertical direction, and the value is 0 for the horizontal direction). The effective water saturation $S_{\omega}$ can be expressed as follows:

$$
S_{\omega}=\frac{\theta_{\omega}-\theta_{\gamma}}{\theta_{s}-\theta_{\gamma}},
$$

where $\theta_{\omega}$ is the volume water content, $\theta_{\gamma}$ is the residual water content, and $\theta_{s}$ is the saturated water content (i.e., 1.0). With (2), we can rewrite (1) as

$$
\frac{\partial S_{\omega}}{\partial t}=\frac{1}{\varphi} d i \tau\left(\frac{K_{\omega \cdot i} K_{\omega \cdot r}}{\mu_{\omega}}\left(\nabla P_{\omega}+\rho_{\omega} g F^{m}\right)\right),
$$

where $\varphi=\theta_{s}-\theta_{\gamma}$ is the apparent porosity in water (in this case, the water content is defined by the ratio of the water volume to the sample volume), $K_{\omega \cdot i}$ is the water permeability, $K_{\omega \cdot r}$ is the relative water permeability, $\mu_{\omega}$ is the viscosity of water, $\rho_{\omega}$ is the density of water, $g$ is the acceleration of gravity, and $P_{\omega}=\rho_{\omega} h g$ is the water pressure. In the nonsaturated case, $P_{\omega}=P_{g}-P_{c}$, where $P_{g}$ is the gas pressure and $P_{c}$ is the capillary pressure.

There are three unknown parameters in (3): $S_{\omega}, K_{\omega \cdot r}$, and $P_{c}\left(K_{\omega \cdot i}\right.$ and $\varphi$ are constant and directly determined by laboratory experiments, and $\mu_{\omega}$ is equal to $\left.1.0 \times 10^{-3} \mathrm{~Pa} \cdot \mathrm{s}\right)$. Therefore, (3) requires two additional equations to solve, which are presented as follows.

2.2. Kelvin-Laplace Equation. The Kelvin-Laplace equation describes the relationship between capillary pressure $P_{c}$ and relative humidity $\mathrm{RH}$. The relative humidity of the air above the meniscus in a capillary pore is given by the Kelvin equation [29], as cited by Galvin [30]:

$$
\ln (\mathrm{RH})=-\frac{v_{m}}{R T} \frac{2 \gamma \cos \theta}{r},
$$

where $v_{m}$ is the molar volume, $R$ is the universal gas constant, $T$ is the temperature, $\gamma$ is the surface tension, $r$ is the radius of the droplet, and $\theta$ is the contact angle. Indeed, for a porous medium, this equation is assumed to describe the relationship between the inside relative humidity and the maximum radius of the pores, which are filled with water. With the Young-Laplace equation [31, 32]

$$
P_{c}=\frac{2 \gamma \cos \theta}{r}
$$

the relationship between the capillary pressure $P_{c}$ and the relative humidity $\mathrm{RH}$ is

$$
P_{c}=-\frac{R T}{v_{m}} \ln (\mathrm{RH}) .
$$

2.3. Retention and Relative Permeability Models. The relationship between water saturation $S_{\omega}$ and the capillary pressure $P_{c}$ is defined by the Van Genuchten (VG) model [33]:

$$
S_{\omega}=\left(1+\left(\frac{P_{c}}{P_{r}}\right)^{n}\right)^{-m},
$$

where $m=1-1 / n$ and $P_{r}$ are two parameters that are related to the pore size distribution of the porous medium. 


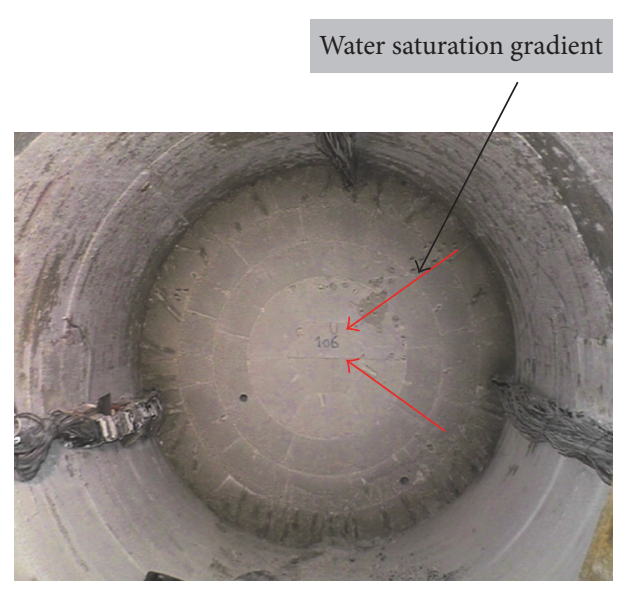

FIgURE 1: In situ situation [25].

The sorption isotherm, which reflects the relationship between the water saturation and the relative humidity, can be determined by the Van Genuchten model and the YoungLaplace equation. Using laboratory experimental results, parameters $n$ and $P_{r}$ can be determined by the least-squares method. [34]:

The relative permeability is given by the Mualem model

$$
\begin{aligned}
& K_{\omega, r}=S_{\omega, j}^{1 / 2}\left(\frac{\int_{0}^{S_{\omega, j}}\left(d S_{\omega} / P_{c}\right)}{\int_{0}^{1}\left(d S_{\omega} / P_{c}\right)}\right)^{2}, \\
& K_{g, r}=\left(1-S_{\omega, j}^{1 / 2}\right)\left(\frac{\int_{0}^{S_{\omega, j}}\left(d S_{\omega} / P_{c}\right)}{\int_{0}^{1}\left(d S_{\omega} / P_{c}\right)}\right)^{2} .
\end{aligned}
$$

Based on the Van Genuchten model, (5) and (6) can be rewritten as follows:

$$
\begin{aligned}
& K_{\omega, r}=S_{\omega, j}^{1 / 2}\left(1-\left(1-S_{\omega, j}^{1 / m}\right)^{m}\right)^{2} \\
& K_{\omega, g}=\left(1-S_{\omega, j}\right)^{1 / 2}\left(1-\left(1-S_{\omega, j}^{1 / m}\right)^{m}\right)^{2 m} .
\end{aligned}
$$

For all tests, the temperature was maintained at $20^{\circ} \mathrm{C}$; therefore, the temperature effect was neglected in our numerical simulations. The effect of water gravity was also assumed to be negligible.

\section{Geometric Model and Boundary Conditions}

3.1. Modelling Scheme Design. In situ experiments require several years to several decades. Therefore, laboratory experiments are used to provide useful data for the design and construction of in situ geological repositories and essential parameters for numerical modelling. For the in situ model, as shown in Figure 1, a significant water saturation gradient is observed between the core and the periphery of the buffer because of underground water seepage [25]. The partially saturated core is gradually saturated with water because the

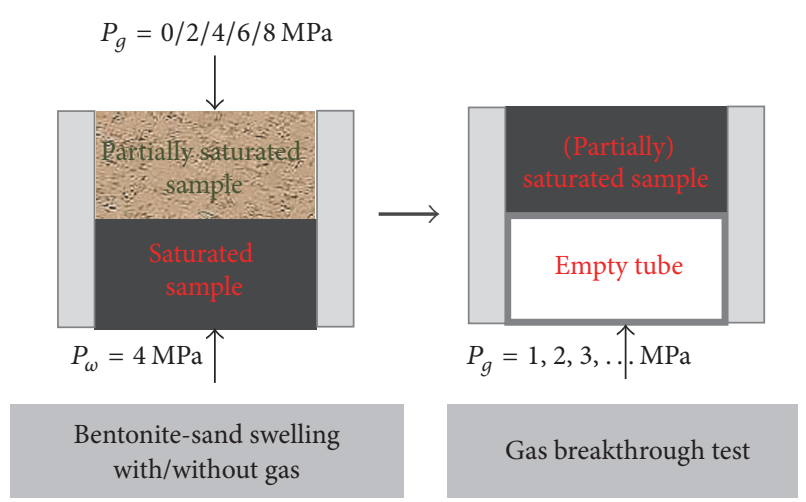

FIgURE 2: Experimental scheme.

saturated peripheral samples are in direct contact with underground water from the surrounding host rock. To reproduce this phenomenon, an original laboratory experiment and a numerical model were established.

Figure 2 shows two samples in a triaxial cell: a fully saturated sample and a partially saturated sample (just after compaction) placed above the fully saturated sample [6]. In a first stage, water and gas were simultaneously injected from the top and bottom sides. The upper sample was supplied with water by the lower sample to realistically simulate an in situ case. In a second stage, the lower sample was removed and replaced by an empty tube. Gas was injected from the bottom side, and the gas pressure was increased from $1 \mathrm{MPa}$ with a step of $1 \mathrm{MPa}$ until a continuous flow was detected. First, when a discontinuous gas flow was detected at the downstream side, the corresponding upstream gas injection pressure was defined as a discontinuous gas breakthrough pressure. Then, the gas pressure was continuously increased. When a continuous gas flow was detected, the corresponding upstream gas injection pressure was defined as the continuous gas breakthrough pressure. More details regarding the definition of discontinuous/continuous gas breakthrough pressures can be found in Liu et al. $[5,6]$.

Numerical modelling was performed using essential parameters and proper boundary conditions measured during the experimental tests. In this study, we only simulated the first stage of the experiment (see Table 1).

3.2. Model Setup. Simulations were performed with the finite element software "Code_Aster" (Code of Structural Analysis and Thermomechanics For Studies and Research, EDF, France). This code is a general code for thermomechanical calculations and includes a series of analytical methods and nonlinear multiphysical modelling. The finite element method (FEM) was implemented for discretization. The "THM" module of "Code_Aster" was used to treat the continuum mechanics equations using the theory of unsaturated porous media and assuming completely coupled mechanical, thermal, and hydraulic phenomena. In our study, the "AXIS_HH2D" model was selected from the "THM" module. "AXIS" indicates axisymmetry, "HH2" indicates hydraulic modelling with two unknown pressures and two 
TABLE 1: Numerical modelling and laboratory experiment schemes.

\begin{tabular}{|c|c|c|c|c|}
\hline \multirow[t]{2}{*}{ Category } & \multirow[t]{2}{*}{ Number } & \multicolumn{2}{|c|}{$\begin{array}{c}\text { Boundary condition } \\
\text { (water/gas injection test) }\end{array}$} & \multirow{2}{*}{$\begin{array}{c}\text { Boundary condition } \\
\text { (gas breakthrough test) } \\
\mathrm{MPa}\end{array}$} \\
\hline & & $P_{g}(\mathrm{MPa})$ & $P_{\omega}(\mathrm{MPa})$ & \\
\hline \multirow{5}{*}{ Numerical modelling } & S-1 & 0 & 4 & N/A \\
\hline & S-2 & 2 & 4 & N/A \\
\hline & $S-3$ & 4 & 4 & N/A \\
\hline & S- 4 & 6 & 4 & N/A \\
\hline & S-5 & 8 & 4 & N/A \\
\hline \multirow{5}{*}{ Laboratory experiment } & E-1 & 0 & 4 & \multirow{5}{*}{$\begin{array}{l}\text { Gas pressure is injected from the } \\
\text { bottom side with } P_{g}=1,2,3,4,5 \text {, } \\
\ldots \text { until continuous gas flow was } \\
\text { detected at the other side. }\end{array}$} \\
\hline & E-2 & 2 & 4 & \\
\hline & E-3 & 4 & 4 & \\
\hline & E-4 & 6 & 4 & \\
\hline & E-5 & 8 & 4 & \\
\hline
\end{tabular}

Note. $P_{g}$ is gas pressure, and $P_{\omega}$ is water pressure.

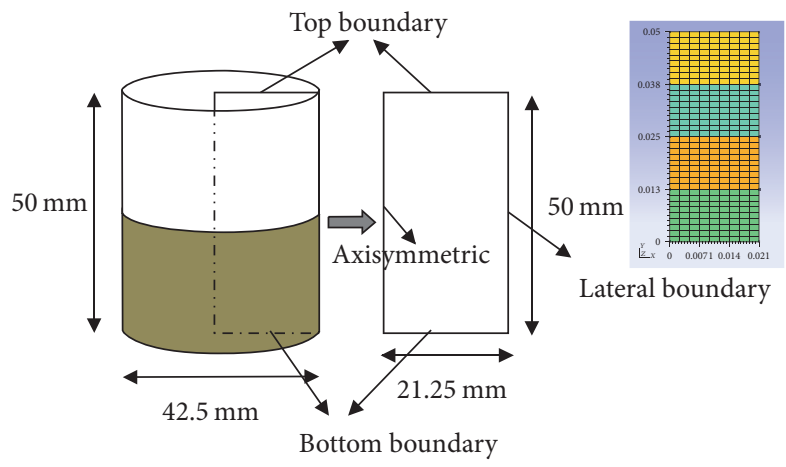

Figure 3: Geometric model and finite element mesh.

components, and " $\mathrm{D}$ " indicates that the points of integration are taken at the tops of the elements. This treatment enables one to diagonalize data matrices to avoid hydraulic oscillation problems.

The boundary and initial conditions of the tests enabled an axisymmetric analysis (see Figure 3). The mesh consisted of quadratic and quadrangular elements (QUAD8). As shown in Figure 3, a two-dimensional $50 \mathrm{~mm}$ (height) $\times 21.5 \mathrm{~mm}$ (radius) axisymmetric finite element model was established which was identical to the sample size in the laboratory experiment. There were 1387 nodes and 451 elements in the model. Monitoring points along the axial and radial directions were selected to record the evolution of the saturation degree versus time (see Figure 4).

3.3. Initial Condition. The "AXIS_HH2D" model cannot directly define the initial saturation by $S_{\omega}$. Therefore, we used the capillary pressure to express the initial water saturation. For the lower sample, a water saturation $S_{\omega}=1.0$ corresponded to a capillary pressure $P_{c}=0$. Theoretically, the capillary pressure must be infinite to define a saturation level of 0 , which is impossible in numerical simulations. Therefore, a large capillary pressure was applied to ensure that $S_{\omega} \leq 0.01$. For the upper sample, the bentonite-sand mixture received

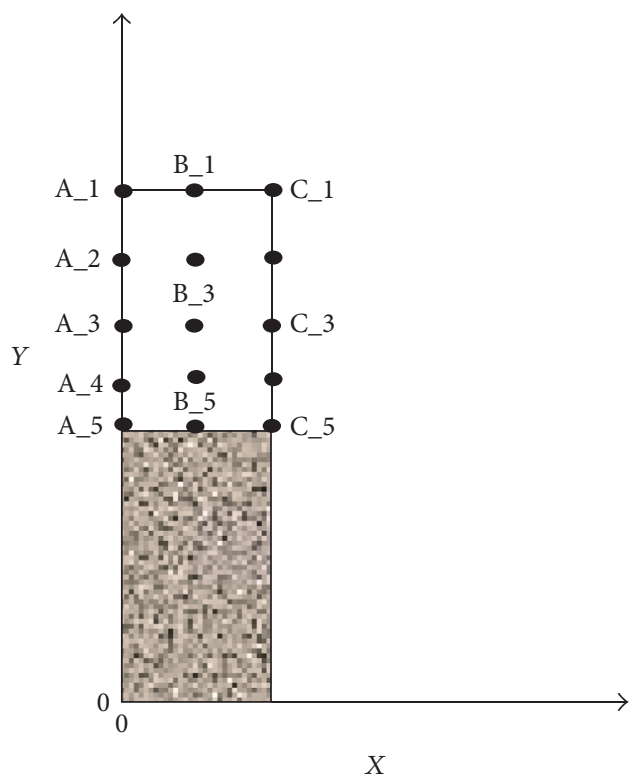

FIGURE 4: Layout of the monitoring points.

an atmosphere at a controlled relative humidity $(\mathrm{RH}=85 \%)$ before compacting. Thus, the relevant capillary pressure $P_{c}$ was $2.21 \times 10^{7} \mathrm{~Pa}$ (see Figure 5).

The values of the main parameters used for the numerical modelling are shown in Table 2. The parameters $S_{r}, S_{\max }$, $R, \rho_{\omega}, T$, and $v_{m}$ were kept constant in all simulations. $K_{\omega}$ and $\varphi$ were measured by the laboratory experiments. To obtain the parameters $P_{r}$ and $n$, a series of water retention tests was performed to obtain the relationship between water saturation $S_{\omega}$ and relative humidity RH (Figure 6). Then, the least-squares method was used to calculate $P_{r}$ and $n$.

3.4. Boundary Conditions. For the axisymmetric model, there are three types of boundary conditions: a bottom boundary, a top boundary, and a lateral boundary (Figure 3). Mechanical boundary conditions require zero displacement 


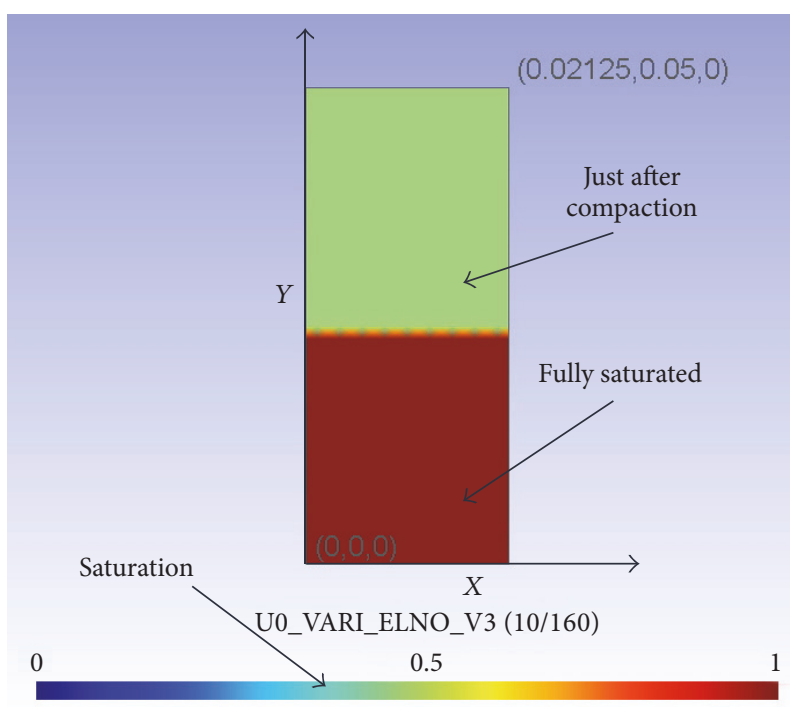

Figure 5: Initial state of the bentonite-sand sample.

TABLE 2: Material properties for numerical modelling.

\begin{tabular}{lccc}
\hline Parameter & Symbol & Unit & Value \\
\hline Residual saturation & $S_{r}$ & - & 0 \\
Maximum saturation & $S_{\max }$ & - & 0.999999 \\
Perfect gas constant & $R$ & - & 8.3144 \\
Water density & $\rho_{\omega}$ & $\mathrm{kg} / \mathrm{m}^{3}$ & 1000 \\
Water permeability & $K_{\omega}$ & $\mathrm{m}^{2}$ & $6.0 \times 10^{-21}$ \\
Porosity & $\varphi$ & - & 0.363 \\
Van Genuchten's parameters & $n$ & - & 1.25 \\
Van Genuchten's parameters & $m=1-1 / n$ & - & 0.2 \\
Van Genuchten's parameters & $P_{r}$ & $\mathrm{MPa}$ & $2.54 E+06$ \\
Perfect gas constant & $R$ & - & 8.3144 \\
Temperature & $T$ & $\mathrm{~K}$ & 295 \\
Molar volume & $v_{m}$ & $\mathrm{~mol} / \mathrm{L}$ & $1.80 E-05$ \\
\hline
\end{tabular}

in the vertical direction at the bottom and the top of the sample and zero radial displacement on the lateral side of the sample. The flow boundary conditions contained water and gas flows. Specifically, the bottom boundary was defined to be in direct contact with water $\left(P_{\omega}=4 \mathrm{MPa}\right)$, the top boundary in direct contact with gas $\left(P_{g}=0\right.$, and $\left.8 \mathrm{MPa}\right)$, and the lateral boundary in contact with water and gas (Figure 2). The distributions of gas pressure and water pressure along the height direction were linear (after the hydraulic cutoff), which has been shown by laboratory experiments [6]. For simplicity, the gas and water pressures should decrease systematically along the height direction (Figure 7).

\section{Results and Discussion}

4.1. Water Saturation of the Bentonite-Sand Sample without Gas: $P_{\omega}=4 \mathrm{MPa} ; P_{g}=0 \mathrm{MPa}$. The overall evolution of the water saturation degree of the sample is presented in Figure 8 (a) as a function of time. A fully water-saturated state was clearly obtained on the 29th day, which was consistent

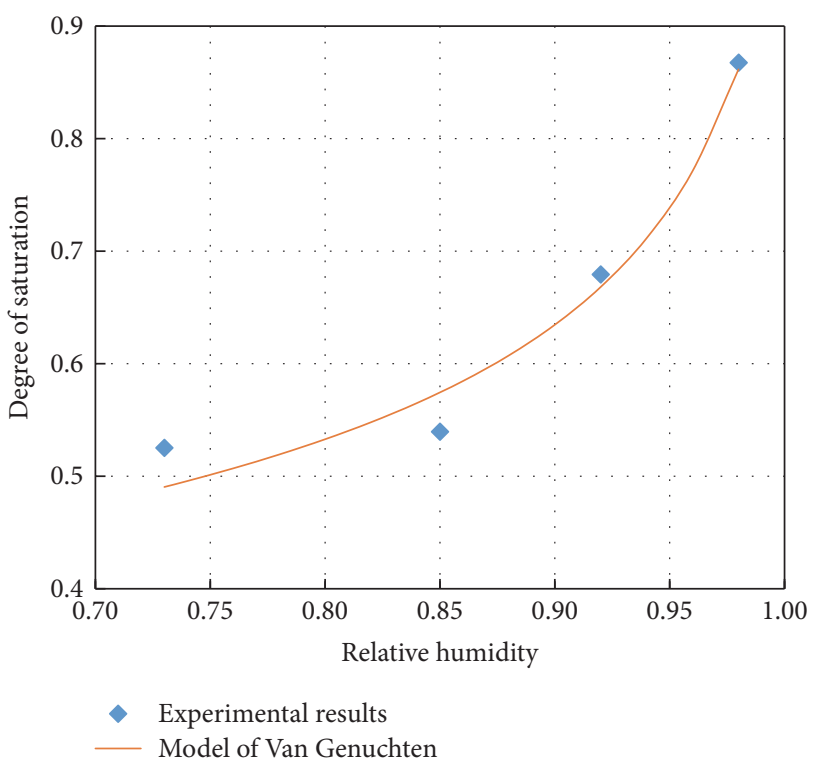

FIGURE 6: Determination of the VG model parameters in the water retention test.

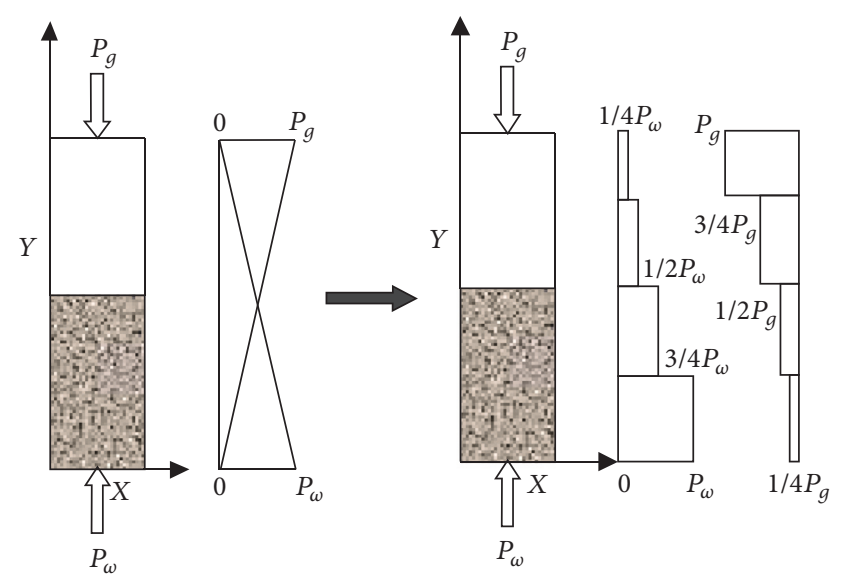

FIGURE 7: Gas and liquid boundary conditions.

with the experimental results (see Figure 8(b)); that is, the swelling pressure of the upper bentonite-sand sample became stable after the 28th day. In the laboratory experiment, we were unable to judge the evolution of the water saturation degree because the sample could not be removed during the experiment. Therefore, the evolution of the swelling pressure was the only indicator to determine the water saturation degree before the gas breakthrough test.

As shown in Figure 8(a), water invasion gradually occurred from the periphery to the centre of the sample. In the experiment, as soon as a water pressure of $4 \mathrm{MPa}$ was applied to the lower sample, the water flow permeated into the upper sample from the top surface of the lower sample and the lateral (right side) and top surfaces of the upper sample. This was due to an initial clearance between the sample and the tube inner surface (Figure 9). In the numerical simulation, this phenomenon was realized by applying water pressure 

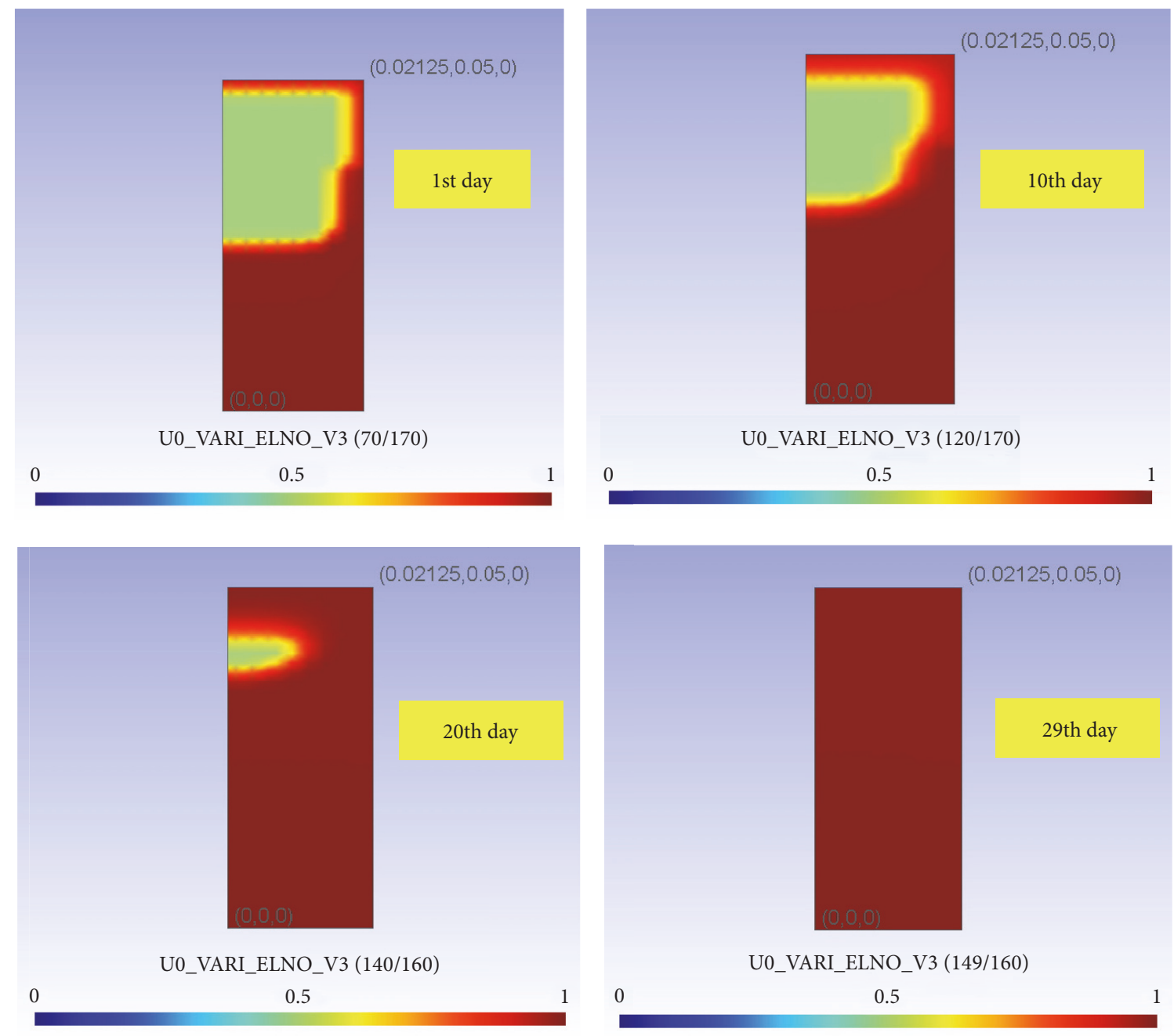

(a)

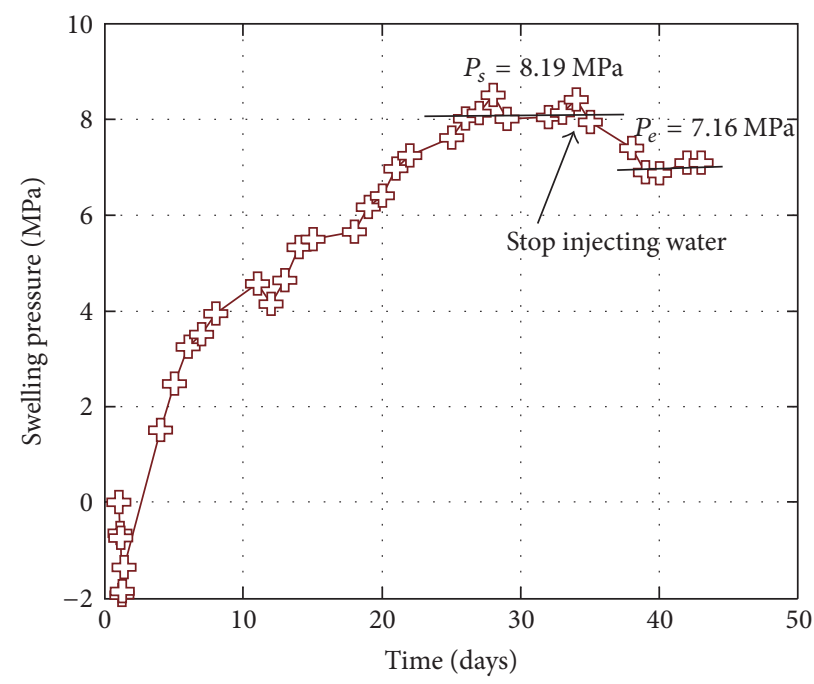

־- Swelling pressure (MPa)

(b)

FIGURE 8: (a) Evolution of the water saturation degree of the bentonite-sand sample with time on the 1st, 10th, 20th, and 29th days (S-1); (b) evolution of the swelling pressure with time: experimental results [6]. 


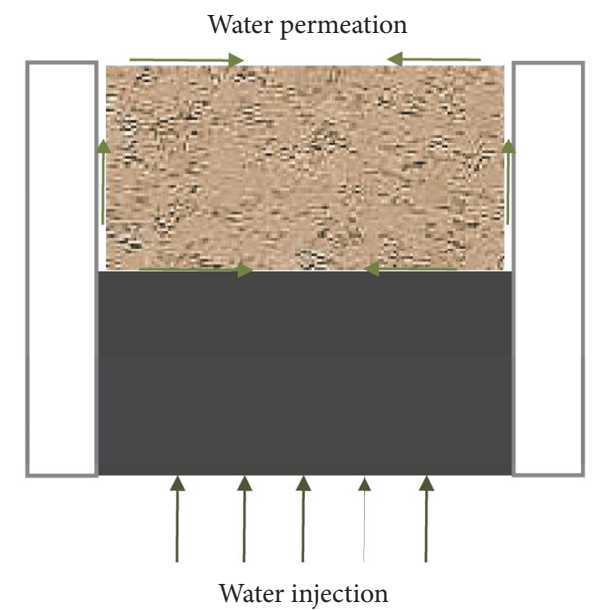

FIGURE 9: Schematic diagram of the water permeation.

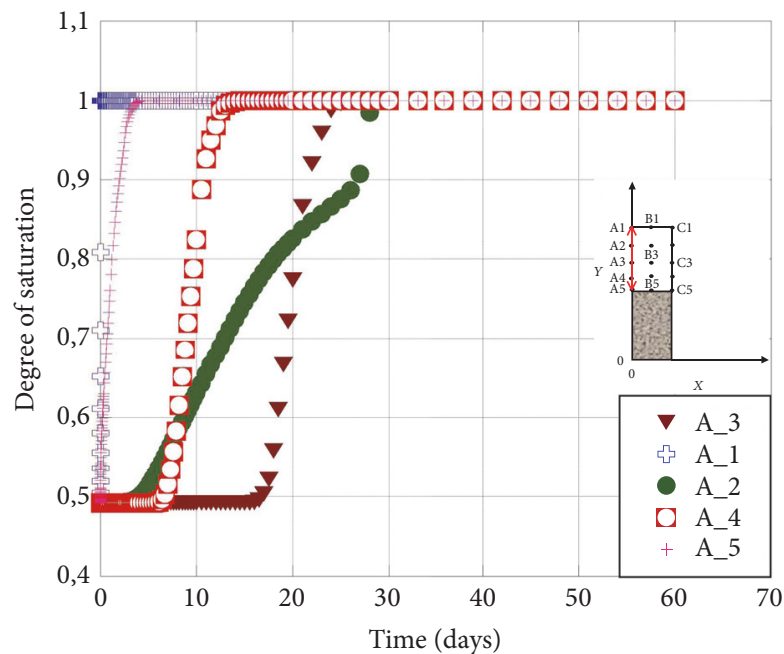

(a)

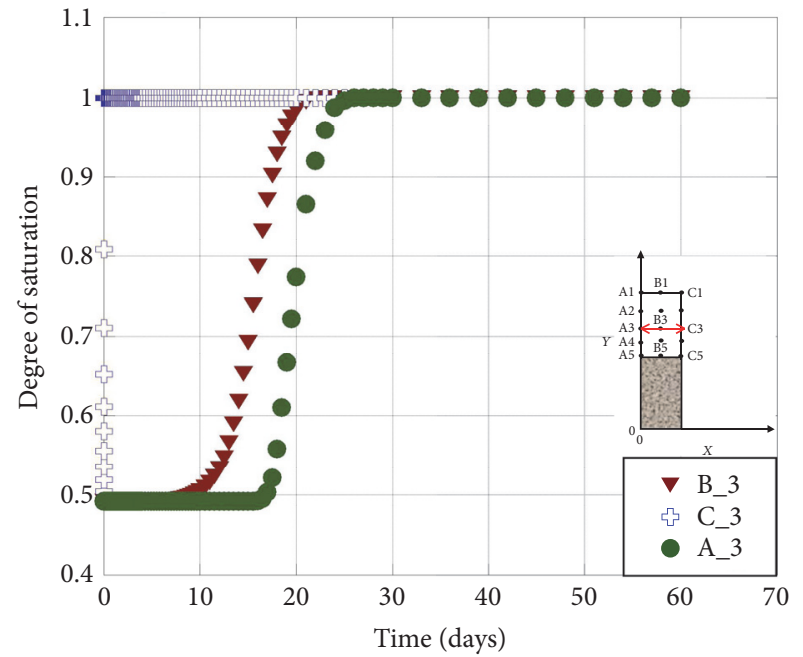

(b)

FIGURE 10: Evolution of the water saturation degree of the monitoring points as a function of time: (a) radial direction; (b) axial direction.

around the boundaries (see Figure 7). Therefore, a significant water saturation gradient was present among the lateral and top surfaces and core. This phenomenon was also observed by the FBEX in situ test [25]. A significant water saturation gradient was observed due to water invasion from the host rock; the water content increased from the axis of the gallery towards the gallery wall (see Figure 1).

Figures 10(a) and 10(b) show the evolution of the water saturation degree of monitoring points at different parts of the sample: from the external surface to the centre of the sample. The water saturation profile changed with time because of the redistribution of moisture. The increasing speed of the water saturation degree was clearly dependent on the distance to the water source, that is, the top surface of the lower sample and the top and lateral surfaces of the upper sample. As shown in Figures $10(\mathrm{a})$ and 10 (b), 17 days were required for moisture to arrive at point $\mathrm{A} 3$, whereas 4 days and 9 days were required for water to reach point $\mathrm{A} 2$ and point $\mathrm{B} 3$, respectively. However, all monitoring points were completely water-saturated after 29 days, which was close to the stabilization time of the swelling pressure of the bentonite sample (see Figure 8(b)).

4.2. Water Saturation of the Bentonite-Sand Sample with $P_{\omega}=$ $4 \mathrm{MPa}$ and $\mathrm{P}_{g}=2 \mathrm{MPa}$. Figure 11 shows the overall evolution of the water saturation degree of the sample versus time at $P_{g}=2 \mathrm{MPa}$ and $P_{\omega}=4 \mathrm{MPa}$. No significant differences were observed with or without $2 \mathrm{MPa}$ of gas. However, more time was required for the upper sample to become fully watersaturated, that is, 29 days versus 78 days. The top and upper right surfaces of the sample were not fully but close to fully water-saturated (Figures 11 and 12, point A1) because of the low applied gas pressure. This result was also likely due to coupling effects between the water and gas pressures. In this case, water pressure played a predominant role in the water saturation process. 

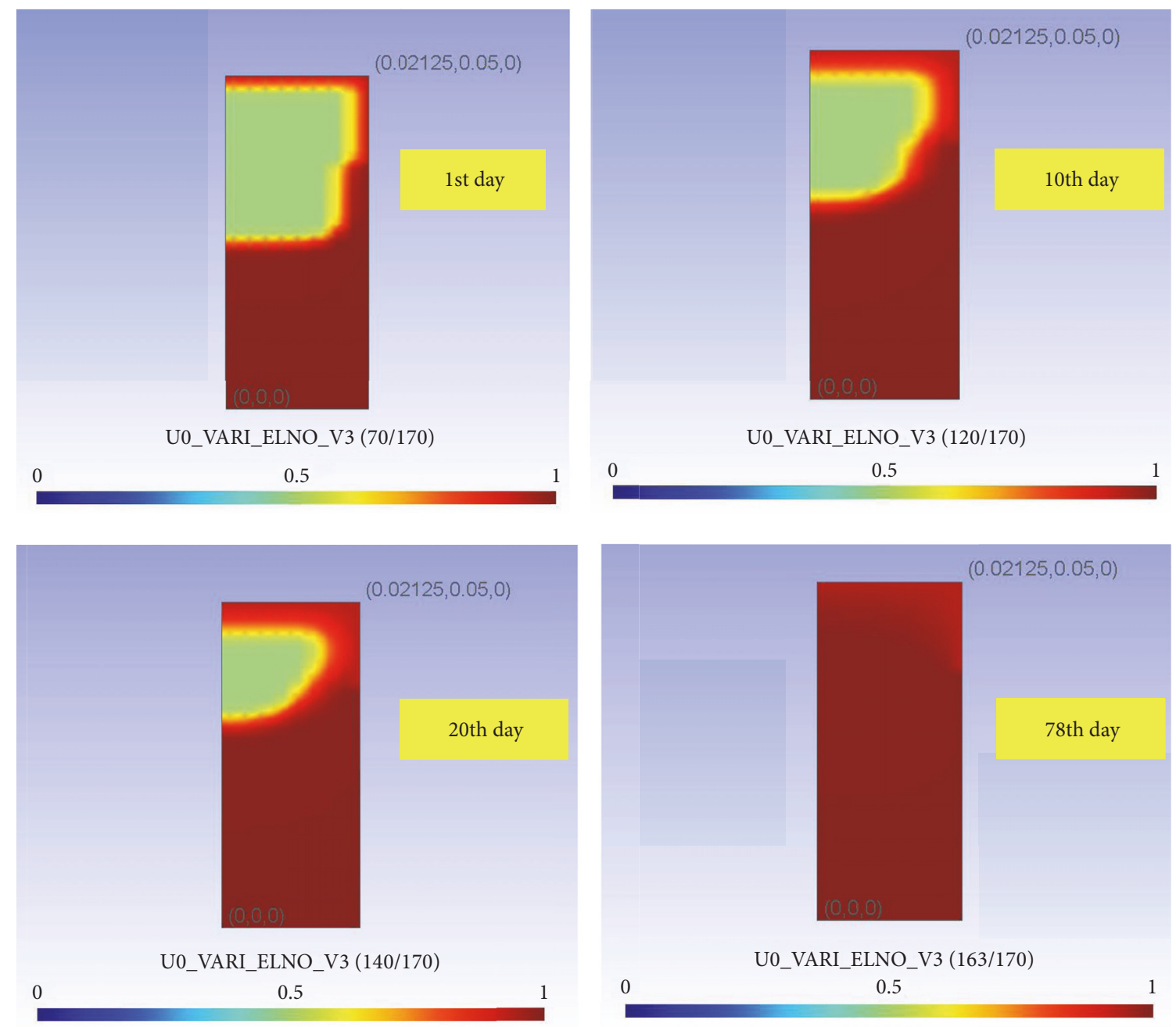

FIGURE 11: Evolution of the water saturation degree of the bentonite-sand sample with time on the 1st, 10th, 20th, and 78th days (S-2).

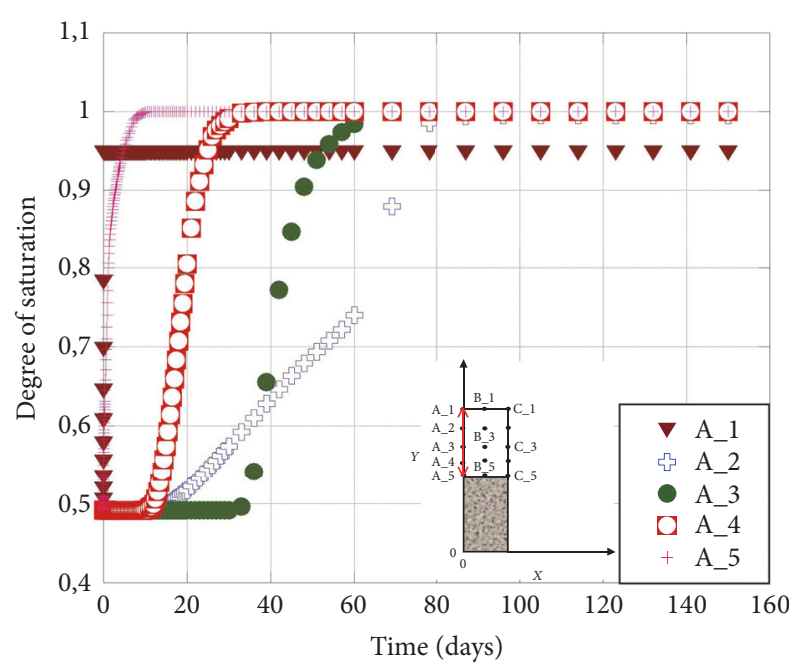

(a)

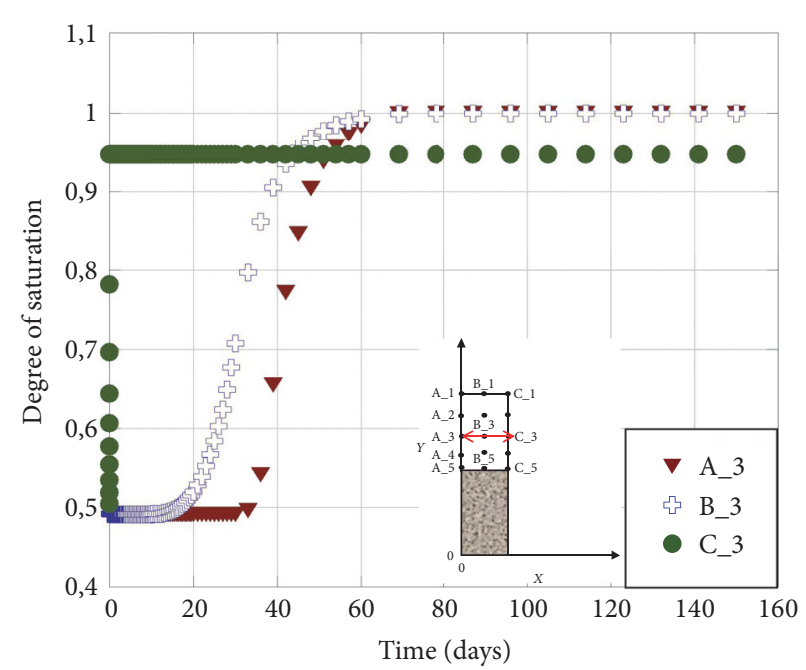

(b)

FIGURE 12: Evolution of the water saturation degree of the monitoring points as a function of time in (a) radial direction and (b) axial direction. 

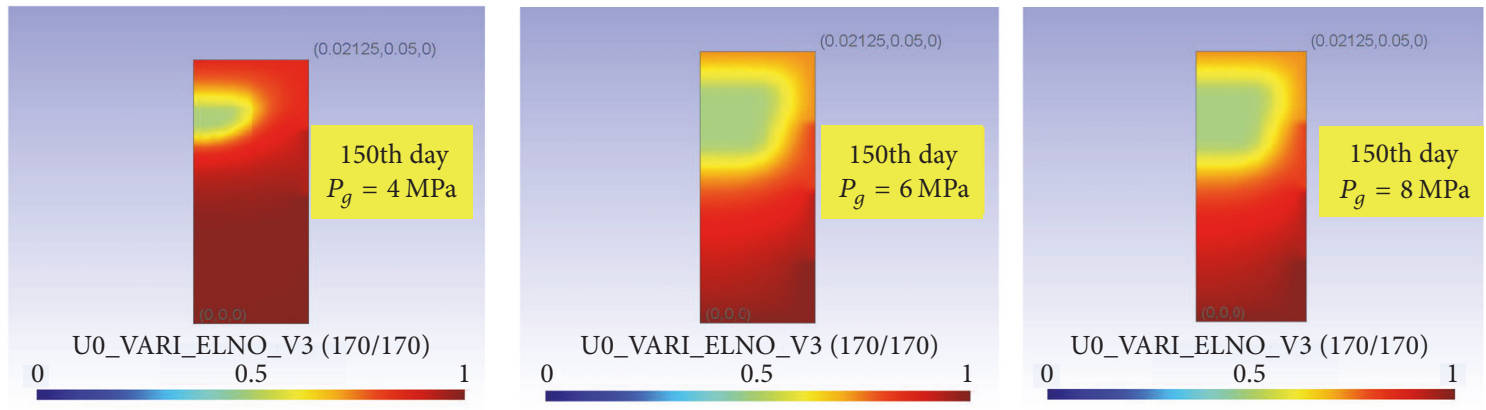

FIGURE 13: Evolution of the water saturation degree of the bentonite-sand sample with time on the 150th day: S-3, S-4, and S-5.

Figures 12(a) and 12(b) show the saturation kinetics of the monitoring points as a function of time. The trends found in series S-1 were confirmed. The water saturation speeds near the water source were higher than those at other sample positions. Additionally, the water saturation gradient appeared in both the axial and radial directions. Because of the applied gas pressure, the water saturation degrees of monitoring points A_1 and C_3 in the external surface were not at full saturation but were close to 1.0 (0.945). This indicated that $2 \mathrm{MPa}$ gas pressure had a limited effect on the water saturation of the upper sample. We can conclude that $2 \mathrm{MPa}$ gas pressure delayed the water saturation process of the upper sample.

4.3. Water Saturation of the Bentonite-Sand Sample with $P_{\omega}=4 \mathrm{MPa}$ and $P_{g}=4,6,8 \mathrm{MPa}$. The simulation results for the bentonite-sand sample under $4 \mathrm{MPa}, 6 \mathrm{MPa}$, and $8 \mathrm{MPa}$ gas pressure and $4 \mathrm{MPa}$ water pressure are shown in Figure 13. Compared with previous results, the results were notably different when a high gas pressure was applied. First, the upper bentonite-sand sample was only partially watersaturated even after 150 days; second, water did not permeate into the core of the upper sample because of the high-applied gas pressure; finally, more time was required for water to enter the pore network of the sample. Similar phenomena were found in the laboratory experiments: the top surface of the upper sample was only partially water-saturated at the end of the first stage $\left(P_{g}=6 \mathrm{MPa}\right.$ and $P_{\omega}=4 \mathrm{MPa}$, see Figure 14(a)). Additionally, more time was required for the swelling pressure of the upper sample to become stabilized (Figure 14(b)). Similarly, gas breakthrough tests showed that gas could pass through the sample at low gas pressure when compared with the case when only water pressure was applied during the swelling test (E-1; see Figure 14(c)). Thus, the bentonite-sand sample lost its sealing ability to gas at this stage due to partial water saturation. Thus, the sealing ability of the bentonite-sand sample was very sensitive to the water saturation degree, which had a close relationship with the water and gas around the sample.

In fact, when gas and water were simultaneously applied, a coupling effect was observed. This coupling effect had an apparent effect on the water saturation of the bentonitesand sample, particularly when the gas pressure was equal to or higher than $4 \mathrm{MPa}$. For series S-4 and S-5, the lower sample was slightly desaturated when the gas pressure was at least $6 \mathrm{MPa}$. As a result, a competitive effect was observed between water pressure and gas pressure: the water saturated the sample, whereas the gas had an opposite effect. The water saturation degree of the lower sample gradually decreased with time, which implied that the higher gas pressure had a stronger effect than the water permeation.

More results can be found at the monitoring points (Figures 15(a) and 15(b)). First, the water saturation degrees of the monitoring points (A_2 and A_4) continued increasing even after 150 days. The water saturation developed more rapidly near the top surface of the lower sample, that is, A_2 versus A_4. Figure 13 shows that it was difficult for water to permeate into the centre of the sample, as shown by the profile of curve A_3 (Figures 14(a) and 14(b)). The water saturation degree of A_3 was stable at 0.5 , which implied that the sample core was not disturbed by either gas or water. However, this was not the case for the periphery area. For example, the water saturation degrees of the monitoring point $\mathrm{C} 3$ were 0.85 (S-3), $0.78(\mathrm{~S}-4)$, and $0.74(\mathrm{~S}-5)$. This indicated that the influences of gas and water on the water saturation of the bentonitesand buffer were largely dependent on the position and the distance to the gas/water source.

4.4. Effect of Gas Pressure on the Water Saturation of the Bentonite-Sand Sample. Regarding the effect of the gas pressure on the water saturation degree of the sample, we analysed points $\mathrm{A} 1$ and $\mathrm{A} 3$; S-1 $\left(P_{g}=0\right.$ and $\left.P_{\omega}=4 \mathrm{MPa}\right)$ was used as a reference. We calculated the differences of the water saturation degrees between S-2, S-3, S-4, and S-5 ( $P_{g}=2,4,6$, and $8 \mathrm{MPa}$ ) and the reference $\mathrm{S}-1$. As shown in Figure 16(a), gas pressure had a limited effect on the water saturation at $2 \mathrm{MPa}$ or lower. As the gas pressure increased, the effect of gas pressure became increasingly apparent. At $P_{g}=8 \mathrm{MPa}$, the water saturation degree of point A1 was only 0.76 , which indicated that gas pressure had a significant influence on the water saturation at point A1.

For point A3, gas pressure had no effects on the evolution of the water saturation degree when the gas pressure was $2 \mathrm{MPa}$ or lower. As shown in Figures 10(a) and 10(b), the water saturation degree of point A3 was 1.0 for S-1 and S-2. However, the water saturation degrees of point A3 remained constant when 4,6 , and $8 \mathrm{MPa}$ gas pressures were applied. This point became fully saturated when $2 \mathrm{MPa}$ or no gas was applied. 


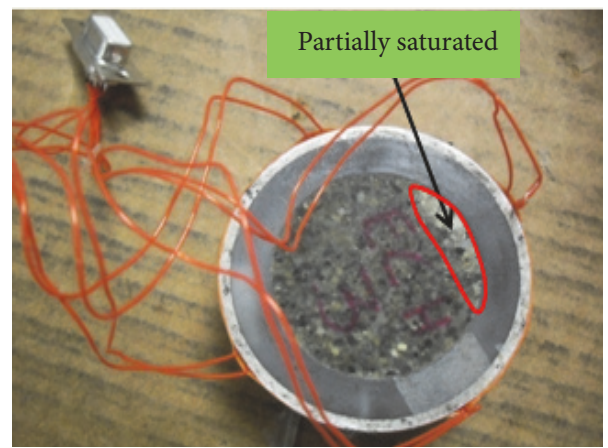

(a)

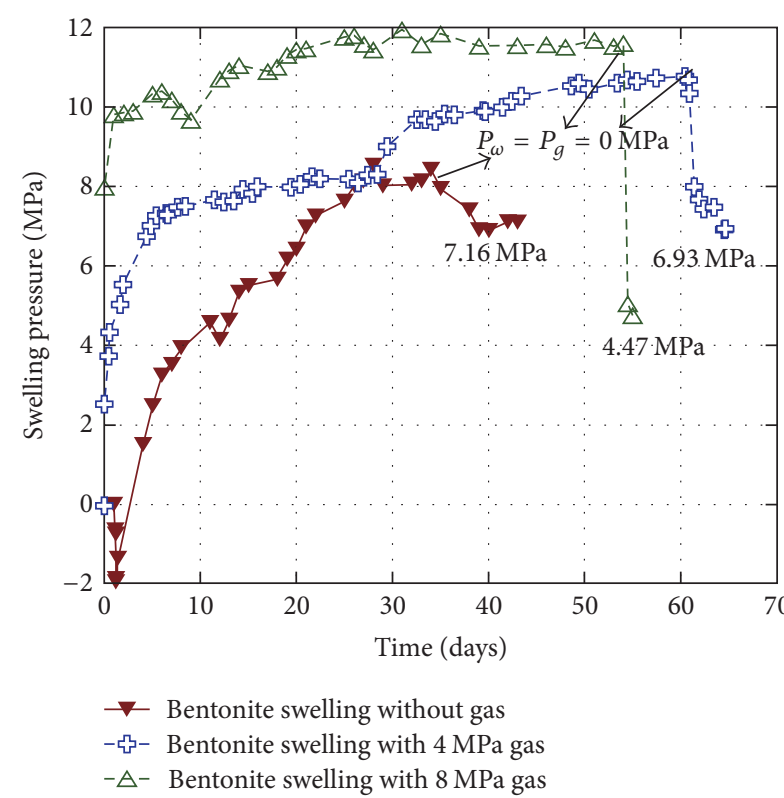

(b)

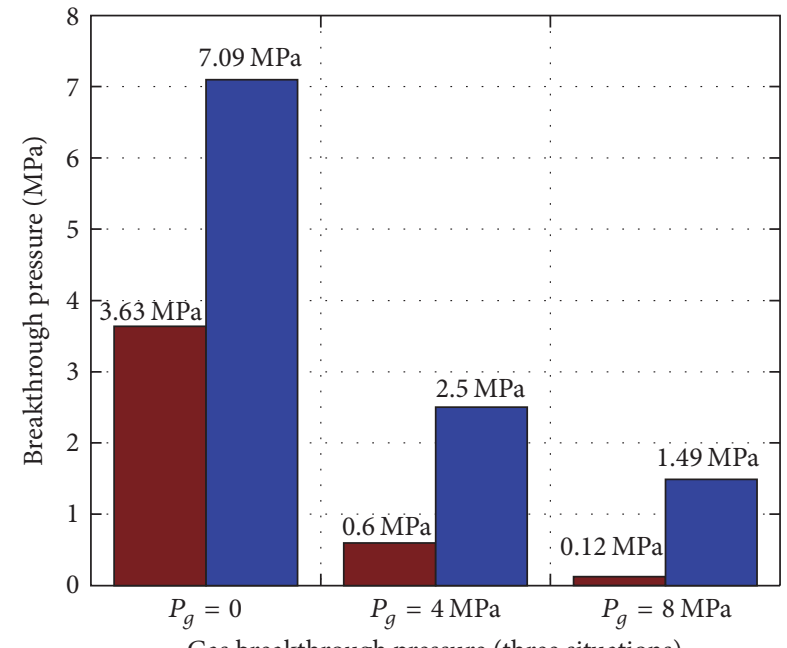

Gas breakthrough pressure (three situations)

Discontinuous breakthrough pressure $(\mathrm{MPa})$

Continuous breakthrough pressure $(\mathrm{MPa})$

(c)

Figure 14: (a) Appearance of the upper sample after the swelling test with $P_{\omega}=4 \mathrm{MPa}$ and $P_{g}=6 \mathrm{MPa}$; (b) evolution of the swelling pressure of the bentonite-sand sample as a function of time; (c) continuous/discontinuous gas breakthrough pressure: E-1, E-3, and E-5.

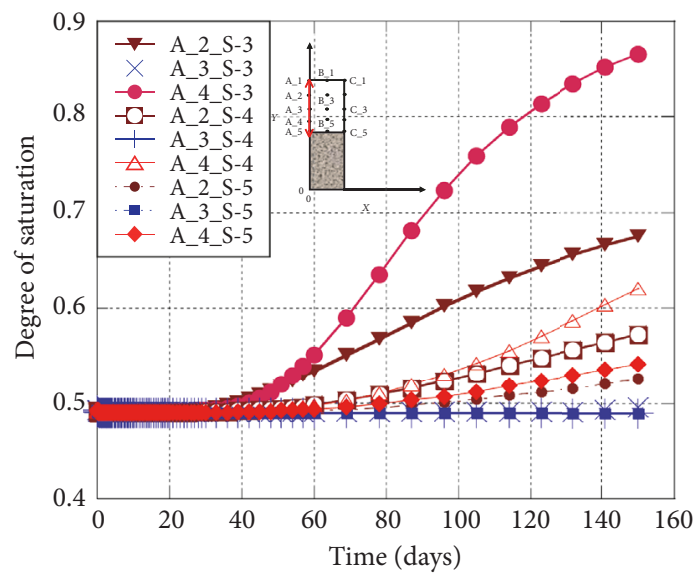

(a)

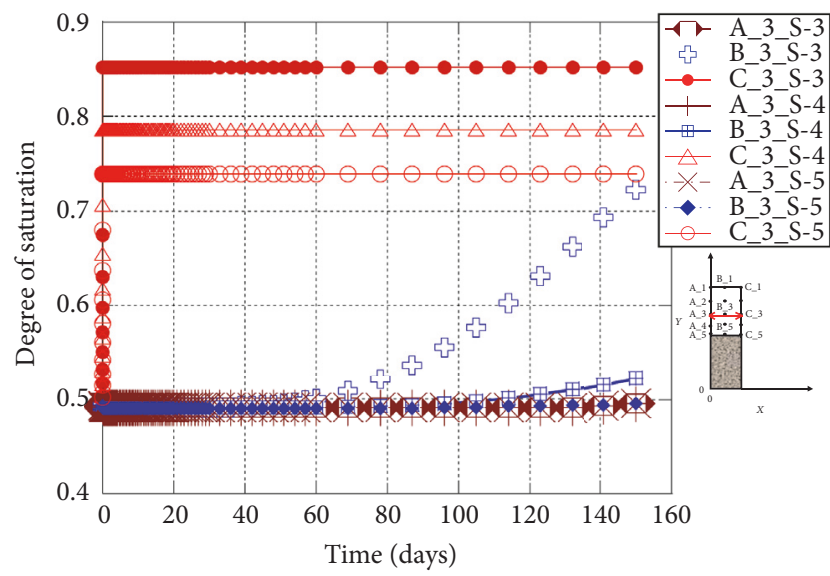

(b)

FIGURE 15: Evolution of the monitoring points of the water saturation degree as a function of time: (a) points A_2, A_3, and A_4; (b) points A_3, B_3, and C_3. 


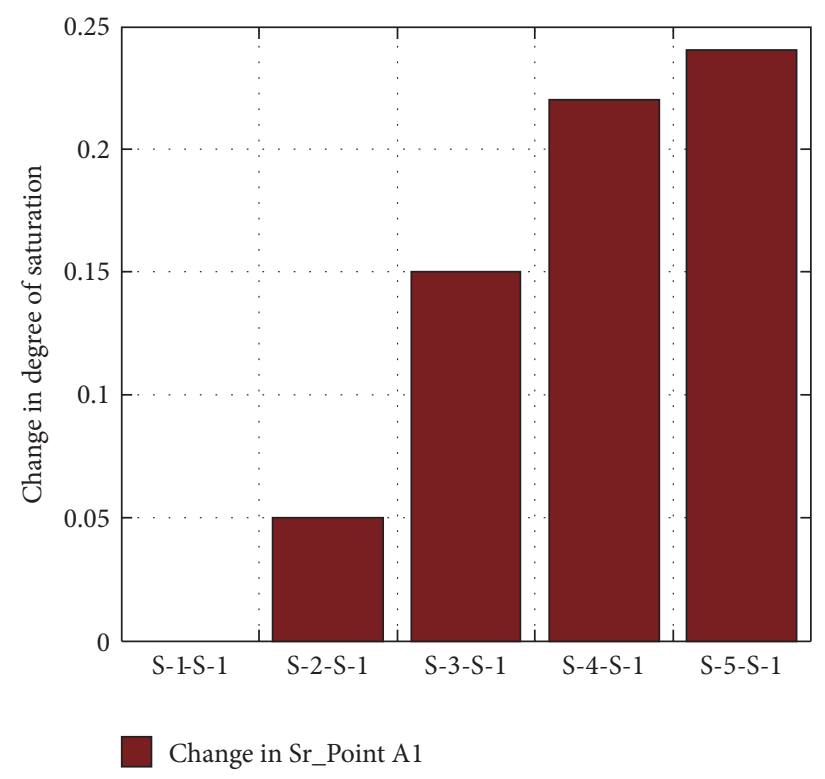

(a)

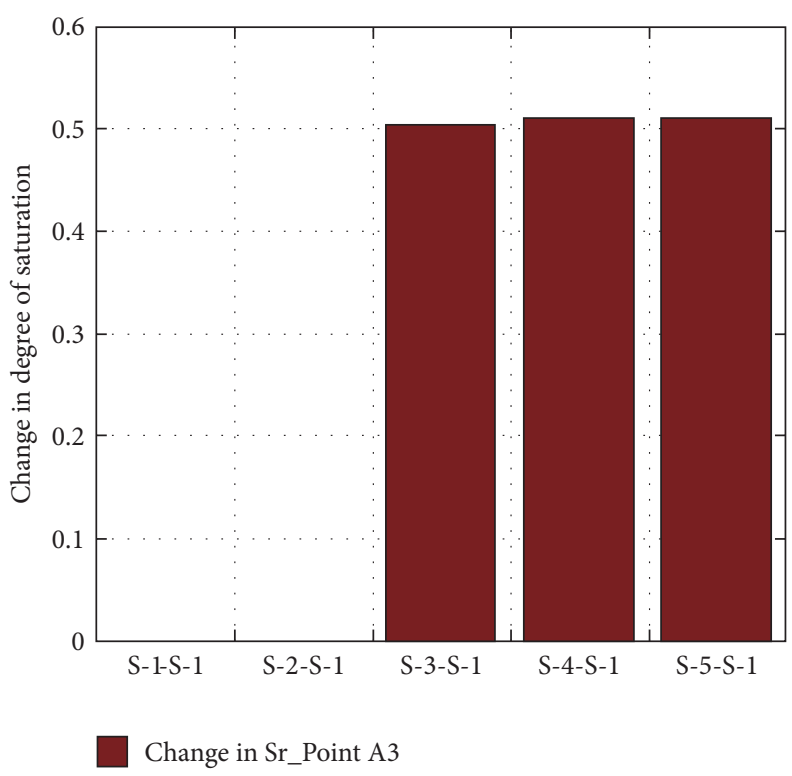

(b)

Figure 16: (a) The changes in Sr for point A1 with a reference of S-1; (b) the changes in Sr for point A3 with a reference of S-1.

This indicated that high gas pressure prevented water from transporting into the pores at this point.

Overall, water and gas are two important factors that affect the water saturation and sealing efficiency of the artificial barrier of a radioactive waste repository. In the initial stage, the gas flow rate was notably low, and water can access the pore network of the buffer material. As a result, progressive water saturation and sealing were obtained over time. As the gas pressure increased, the bentonitesand buffer progressively desaturated, and the sealing ability of the bentonite-sand buffer gradually diminished. When gas release occurred through a part of the bentonite buffer, the gas pressure decreased. Progressive water saturation and sealing were again obtained. This process continued, and the bentonite-sand buffer was saturated and desaturated due to the competition between the water and gas pressures.

\section{Conclusions}

Both laboratory and in situ experiments require long durations and significant funding. Therefore, numerical simulations are essential tools for understanding gas and water flow processes through partially water-saturated bentonite-sand buffer. Regarding the two important factors of water and gas, this study examined their coupling effect, particularly on the water saturation of bentonite-sand samples. Our investigation was performed with five cases; that is, the water saturation of the bentonite-sand sample was tested with different gas pressures and at a constant water pressure. First, a significant water saturation gradient was observed between the core and the surface of the sample during the saturation process. This gradient disappeared after the entire sample was fully saturated (only for series S-1). When a gas pressure was applied, a coupling effect between the water and gas pressures was observed. Water saturated the sample, whereas gas had the opposite effect. The predominant role was determined by the gas or water pressure acting on the pore structure of the bentonite-sand sample. Even for the same sample, the water saturation distribution was not uniform because of boundary condition variations. When the gas pressure was at least $4 \mathrm{MPa}$ (during the swelling process), it was difficult for water to permeate into the pore network of the sample. Hence, high gas pressures had strong effects on the desaturation of the bentonite-sand sample. The water saturation degrees of the upper and lower samples decreased with time when the gas pressure was at least $6 \mathrm{MPa}$. This phenomenon is particularly important. In situ, the voids between the canister and the buffer and between the host rock and the buffer are potential places for gas accumulation. If the gas pressure is sufficiently high, both the buffer and host rock near the buffer are affected. As a result, the sealing efficiency of the entire barrier is affected and should not be overlooked.

\section{Conflicts of Interest}

The authors declare that they have no conflicts of interest.

\section{Acknowledgments}

The authors are grateful for the support provided by the Natural Science Foundation of Jiangsu Province of China (BK20160249) and the Fundamental Research Funds for the Central Universities (China University of Mining and Technology) (2014YC03).

\section{References}

[1] Y. J. Cui, A. M. Tang, C. Loiseau, and P. Delage, "Determining the unsaturated hydraulic conductivity of a compacted 
sand-bentonite mixture under constant-volume and free-swell conditions," Physics and Chemistry of the Earth, vol. 33, no. 1, pp. S462-S471, 2008.

[2] C. A. Davy, F. Skoczylas, P. Lebon, and T. Dubois, "Gas migration properties through a bentonite/argillite interface," Applied Clay Science, vol. 42, no. 3-4, pp. 639-648, 2009.

[3] A. Dueck, "Laboratory results from hydro-mechanical tests on a water unsaturated bentonite," Engineering Geology, vol. 97, no. 1-2, pp. 15-24, 2008.

[4] H. Komine, "Simplified evaluation for swelling characteristics of bentonites," Engineering Geology, vol. 71, no. 3-4, pp. 265-279, 2004.

[5] J.-F. Liu, Y. Song, F. Skoczylas, and J. Liu, "Gas migration through water-saturated bentonite-sand mixtures, COx argillite, and their interfaces," Canadian Geotechnical Journal, vol. 53, no. 1, pp. 60-71, 2015.

[6] J. F. Liu, C. A. Davy, J. Talandier, and F. Skoczylas, "Effect of gas pressure on the sealing efficiency of compacted bentonite-sand plugs," Journal of Contaminant Hydrology, vol. 170, pp. 10-27, 2014.

[7] W. M. Ye, Y. J. Cui, L. X. Qian, and B. Chen, "An experimental study of the water transfer through confined compacted GMZ bentonite," Engineering Geology, vol. 108, no. 3-4, pp. 169-176, 2009.

[8] M. Birgersson, M. Åkesson, and H. Hökmark, "Gas intrusion in saturated bentonite-a thermodynamic approach," Physics and Chemistry of the Earth, vol. 33, no. 1, pp. S248-S251, 2008.

[9] S. T. Horseman, J. F. Harrington, and P. Sellin, "Gas migration in clay barriers," Engineering Geology, vol. 54, no. 1-2, pp. 139-149, 1999.

[10] F. King, L. Ahonen, C. Taxén, U. Vuorinen, and L. Werme, "Copper corrosion under expected conditions in a deep geologic repository," Svensk Kärnbränslehantering AB, vol. 1, 2001.

[11] T. Popp, "tate of the art report on gas transport through interfaces," FORGE Report, 2009, D3.1-R (WP 3.3) - DRAFT.

[12] W. Chen, J. Liu, F. Brue et al., "Water retention and gas relative permeability of two industrial concretes," Cement and Concrete Research, vol. 42, no. 7, pp. 1001-1013, 2012.

[13] C. A. Davy, F. Skoczylas, J.-D. Barnichon, and P. Lebon, "Permeability of macro-cracked argillite under confinement: gas and water testing," Physics and Chemistry of the Earth, vol. 32, no. 8-14, pp. 667-680, 2007.

[14] J.-F. Liu, F. Skoczylas, and J. Talandier, "Gas permeability of a compacted bentonite-sand mixture: coupled effects of water content, dry density, and confining pressure," Canadian Geotechnical Journal, vol. 52, no. 8, pp. 1159-1167, 2015.

[15] C. A. Davy, F. Skoczylas, P. Lebon, and T. Dubois, "Gas migration properties through a bentonite/argillite interface," Applied Clay Science, vol. 42, no. 3, pp. 639-648, 2009.

[16] C. C. Graham, J. F. Harrington, R. J. Cuss, and P. Sellin, “Gas migration experiments in bentonite: Implications for numerical modelling," Mineralogical Magazine, vol. 76, no. 8, pp. 32793292, 2012.

[17] V. Gutiérrez-Rodrigo, M. V. Villar, P. L. Martín, F. J. Romero, and J. M. Barcala, "Gas-breakthrough pressure of FEBEX bentonite," Geological Society, London, Special Publications, vol. 415, no. 1, pp. 47-57, 2015.

[18] W. M. Ye, L. Xu, B. Chen, Y. G. Chen, B. Ye, and Y. J. Cui, "An approach based on two-phase flow phenomenon for modeling gas migration in saturated compacted bentonite," Engineering Geology, vol. 169, no. 2, pp. 124-132, 2014.
[19] M. Fall, O. Nasir, and T. S. Nguyen, "A coupled hydro-mechanical model for simulation of gas migration in host sedimentary rocks for nuclear waste repositories," Engineering Geology, vol. 176, no. 5, pp. 24-44, 2014.

[20] W. J. Xu, H. Shao, J. Hesser, W. Wang, K. Schuster, and O. Kolditz, "Coupled multiphase flow and elasto-plastic modelling of in-situ gas injection experiments in saturated claystone (Mont Terri Rock Laboratory)," Engineering Geology, vol. 157, no. 8, pp. 55-68, 2013.

[21] L. Gonzalez-Blanco, E. Romero, C. Jommi, X. Li, and X. Sillen, "Gas migration in a Cenozoic clay: experimental results andExperimental numerical modelling," Geomechanics for Energy and the Environment, vol. 6, pp. 81-100, 2016.

[22] D. Arnedo, E. E. Alonso, S. Olivella, and E. Romero, "Gas injection tests on sand/bentonite mixtures in the laboratory. Experimental results and numerical modelling," Physics and Chemistry of the Earth, vol. 33, no. 1, pp. S237-S247, 2008.

[23] L. Bénet, É. Blaud, and J. Wendling, "Modelling of water and gas flow through an excavation damaged zone in the CallovoOxfordian argillites in the framework of a single porosity model," Journal of the Geological Society, vol. 443, no. 1, pp. 319332, 2017.

[24] Y. Tawara, A. Hazart, K. Mori et al., "Extended two-phase flow model with mechanical capability to simulate gas migration in bentonite," Geological Society, London, Special Publications, vol. 400, no. 1, pp. 545-562, 2014.

[25] M. V. Villar and A. Lloret, "Dismantling of the first section of the FEBEX in situ test: THM laboratory tests on the bentonite blocks retrieved," Physics and Chemistry of the Earth, vol. 32, no. 8-14, pp. 716-729, 2007.

[26] C. P. Kumar, "Modelling of Unsaturated Flow," in Proceedings of the National Conference on Modern Trends in Water Resources Development and Environmental Management, Vellore Institute of Technology, March 2002.

[27] P. Ngnepieba, X. L. François Dimet, A. Boukong et al., "Identification de paramètres: une application à l'équation de Richards: Arima," p. 127-157, 2002.

[28] L. A. Richards, "Capillary conduction of liquids through porous mediums," Journal of Applied Physics, vol. 1, no. 5, pp. 318-333, 1931.

[29] W. Thomson, "On the equilibrium of a vapour at a curved surface of liquid," Philosophical Magazine, vol. 42, pp. 448-452, 1871.

[30] K. P. Galvin, "A conceptually simple derivation of the Kelvin equation," Chemical Engineering Science, vol. 60, no. 16, pp. 4659-4660, 2005.

[31] P. S. D. Laplace, Traite De Mechanique Celeste, Gauthier Villars, Paris, France, 1808.

[32] T. Young, "An essay on the cohesion of fluids," Philosophical Transactions of the Royal Society of London, vol. 95, pp. 65-87, 1805.

[33] M. T. van Genuchten, "A closed-form equation for predicting the hydraulic conductivity of unsaturated soils," Soil Science Society of America Journal, vol. 44, no. 5, pp. 892-898, 1980.

[34] Y. Mualem, "A new model for predicting the hydraulic conductivity of unsaturated porous media," Water Resources Research, vol. 12 , no. 3, pp. 513-522, 1976. 

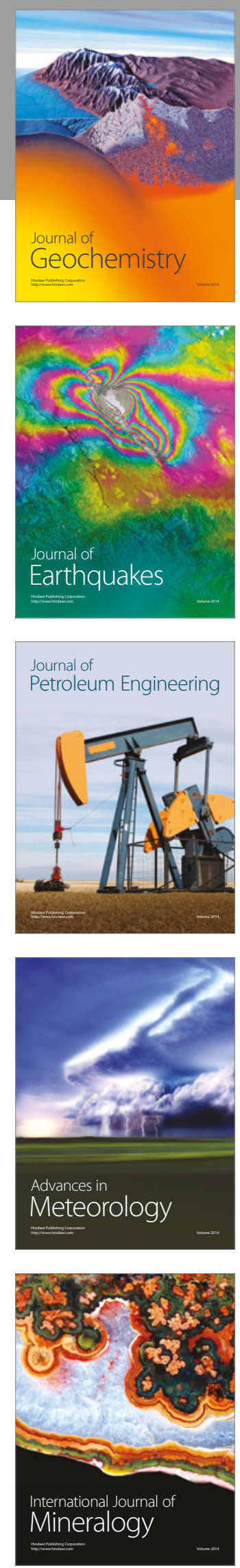
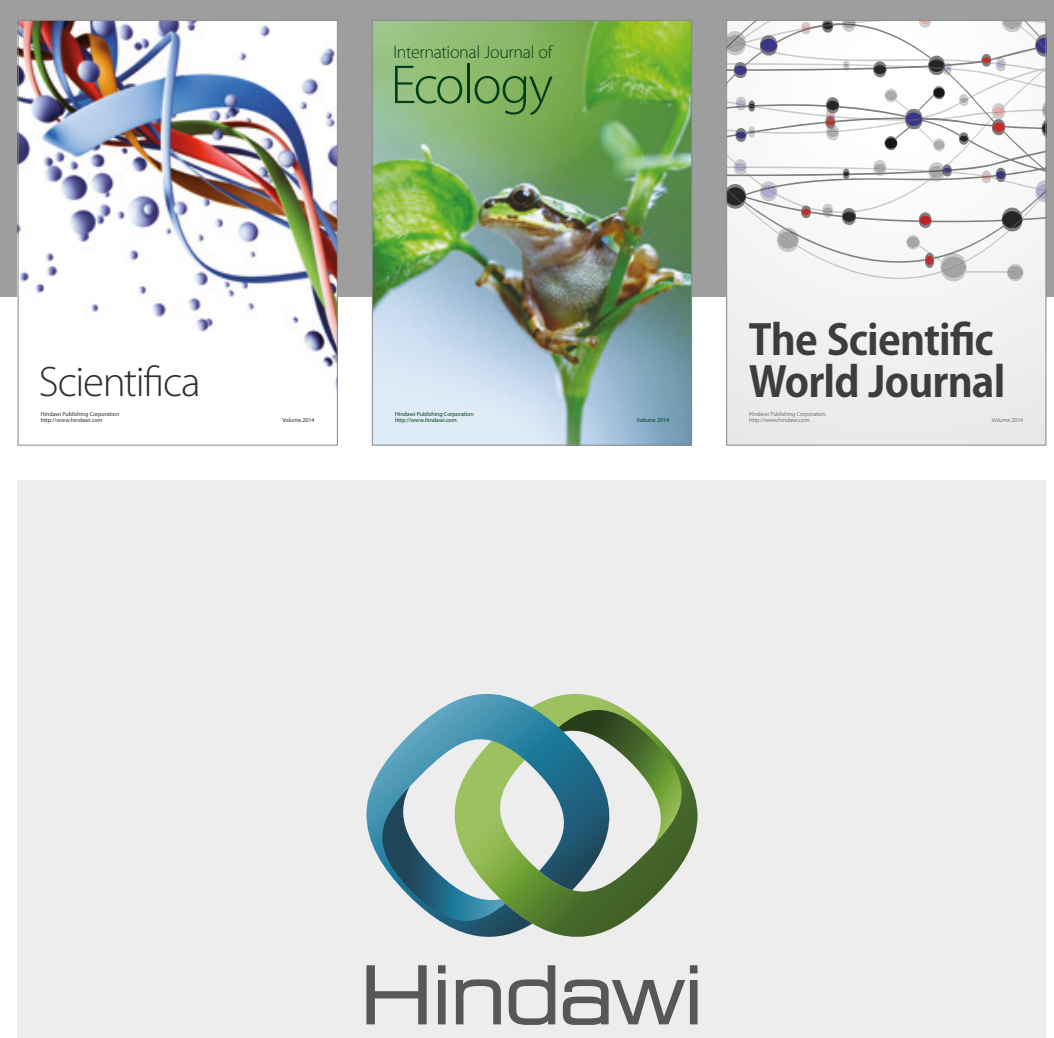

Submit your manuscripts at

https://www.hindawi.com
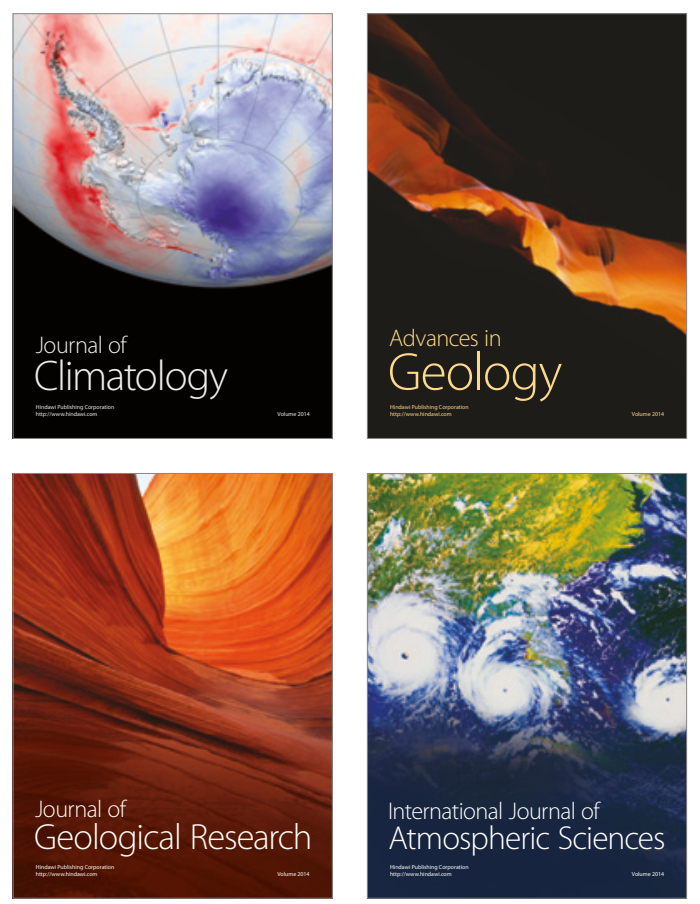

The Scientific

World Journal
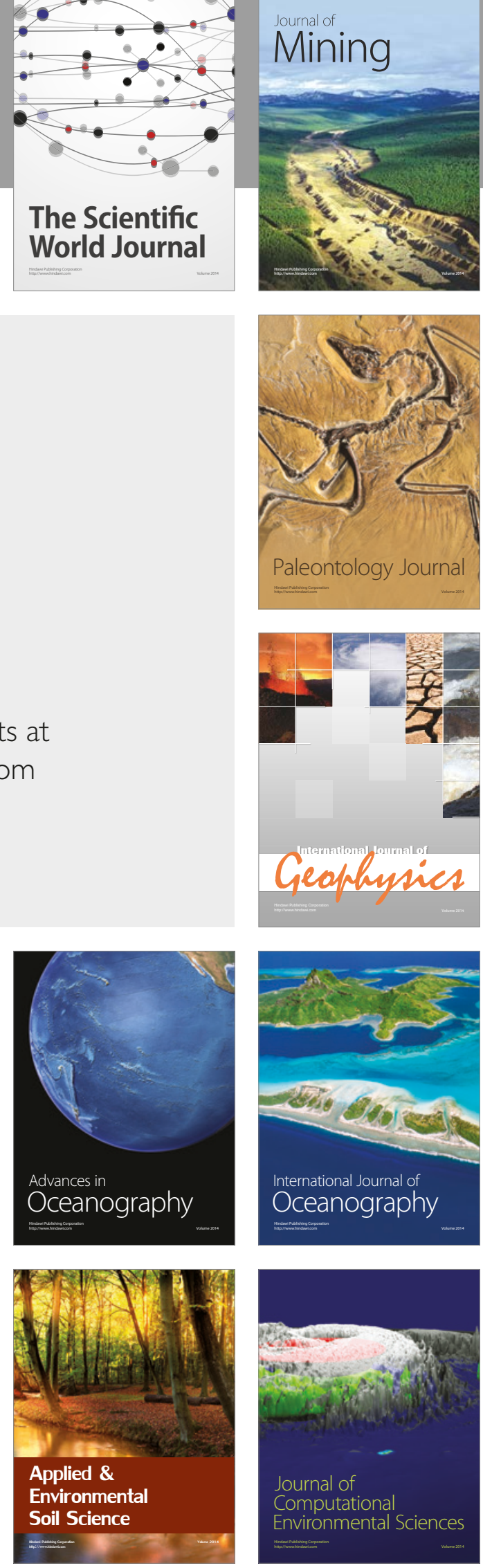